\title{
Variability of metabolic risk factors associated with prehypertension in males and females: a cross-sectional study in China
}

\author{
Bo Liư ${ }^{1}$, Xiaoqi Dong², Yufei Xiao ${ }^{1}$, Xianya Mao ${ }^{1}$, Wensheng Pan³ ${ }^{3}$, Das UN ${ }^{4,5}$, Guangming Qin ${ }^{1}$
}

\author{
'Department of Laboratory, Second Affiliated Hospital, School of Medicine, Zhejiang \\ University, Hangzhou, China \\ ${ }^{2}$ Oral Maxillofacial Surgery, Second Affiliated Hospital, School of Medicine, Zhejiang \\ University, Hangzhou, China \\ ${ }^{3}$ Department of Gastroenterology, Second Affiliated Hospital, School of Medicine, \\ Zhejiang University, Hangzhou, China \\ ${ }^{4}$ BioScience Research Centre, Department of Medicine, Gayatri Vidya Parishad \\ Hospital, GVP College of Engineering Campus, Visakhapatnam, India \\ ${ }^{5}$ UND Life Sciences, USA
}

Submitted: 21 March 2017

Accepted: 29 May 2017

Arch Med Sci 2018; 14, 4: 766-772

DOI: https://doi.org/10.5114/aoms.2018.76066

Copyright @ 2018 Termedia \& Banach

\section{Abstract}

Introduction: Prehypertension is highly prevalent. However, very few studies have evaluated the association of various metabolic risk factors in those with prehypertension and, more importantly, possible differences based on gender.

Material and methods: Data of clinical characteristics were collected from 3891 subjects. Risk factors were analyzed by multiple logistic regression analysis. The areas under receiver operating characteristic curves were compared to assess the discriminatory value of metabolic parameters for predicting prehypertension.

Results: The incidence of prehypertension was 55.9\% (66.9\% of men, $41.1 \%$ of women). Prehypertensives showed clusters of metabolic associations including changes in the levels of plasma high-density lipoprotein cholesterol $(O R=1.550)$, triglycerides $(O R=1.141)$ and fasting blood glucose $(O R=$ 1.320) after adjusting for age, sex, body mass index and smoking. The metabolic associations also showed differences based on gender. For instance, higher total cholesterol $(O R=1.602)$ was the most evident risk factor in men with prehypertension, while higher triglycerides $(O R=1.314)$ and lower high-density lipoprotein cholesterol $(O R=1.729)$ were the main risk factors in women.

Conclusions: Our study suggests that risk associations of prehypertension show gender differences. These results emphasize the importance of health education, active management of blood pressure and timely and effective treatment of abnormal lipid profile in subjects with prehypertension.

Key words: prehypertension, gender, lipids, risk factor.

\section{Introduction}

Prehypertension was first defined by the Seventh Report of the Joint National Committee on Prevention, Diagnosis, Evaluation, and Treatment of High blood pressure (JNC 7). By definition, those who have blood pressure (BP) between 120 and $139 \mathrm{~mm} \mathrm{Hg}$ systolic or 80 and $89 \mathrm{~mm} \mathrm{Hg}$

\author{
Corresponding author: \\ Guangming Qin \\ Department of Laboratory \\ Second Affiliated Hospital \\ School of Medicine \\ Zhejiang University \\ 310009 Hangzhou \\ China \\ Phone: +86571 87783750 \\ E-mail: zejykqgm@163.com
}


diastolic [1] are considered to have prehypertension. Prehypertension is common and affects $25-50 \%$ of adults worldwide. The prevalence was $31 \%$ in the USA, $32 \%$ in Japan, and $40 \%$ in the Ashanti region of Ghana [2-4]. Studies revealed that prehypertension could be linked to subsequent development of hypertension, with annual rates ranging from $8 \%$ to $20 \%$ in studies lasting 2-4 years, and $4 \%$ to $9 \%$ in longer-term studies [5]. Individuals with prehypertension showed a two to threefold higher risk of developing hypertension than those who are normotensive $[6,7]$. Prehypertension also increases the risk of cardiovascular events. In the Framingham study, the risk-factor-adjusted hazard ratio for cardiovascular disease was higher in subjects with high-normal blood pressure (130-139/85-89 mm $\mathrm{Hg}$ ) than those with optimal blood pressure [8]. Several prospective and cross-sectional studies have reported an elevated cardiovascular disease risk among prehypertensives [9-12]. Epidemiological studies have also showed that prehypertension is likely to be associated with increased risk of target-organ damage [5, 13].

Prehypertension is highly prevalent and elevates the risk of incident hypertension, cardiovascular events, and death. Studies have indicated that effective preventative approaches can delay or reduce the progression from prehypertension to hypertension [14]. Hence, risk management and disease prevention for the large proportion of the population with prehypertension are important. However, no effective public health strategy has been employed on this account [15].

To develop strategies to control prehypertension, many studies have explored risk factors associated with prehypertension [16-19]. However, previous studies have been limited to a general population and very few studies have evaluated whether the risk factors are different based on gender. Furthermore, previous studies concentrated on risk factors such as demography, lifestyle habits or traditional risk factors like age and obesity. Few studies have assessed the possible association among metabolic factors such as plasma lipid and glucose abnormalities. Therefore, we aimed to assess the association of prehypertension in terms of metabolic factors, especially their possible differences between males and females, in order to develop more specific prevention strategies.

\section{Material and methods}

\section{Study subjects}

The study was a cross-sectional study of 3891 subjects who underwent a general physical examination in the Second Affiliated Hospital, School of Medicine, Zhejiang University from March 2014 to March 2015. Of all the subjects, there were 2233 men and 1658 women, aged from 18 to 80 years old. All the subjects were asked to complete a questionnaire including gender, date of birth, occupation, marital status, smoking status, alcohol intake history, past medical history, and family history. Current smoker was defined as smoking occasionally or $\geq 1$ cigarette/day [20]. All the subjects in our study were free of cardiovascular and cerebrovascular disease, atherosclerotic disease, cancer, hypotension, hypertension, diabetes, renal disease, hepatic disease, and infectious diseases, consumed no alcohol (0 g/week) [21] and were not on any antihypertensive therapy. All the subjects signed informed consent. The study was reviewed and approved by the institutional review board (IRB) of the Second Affiliated Hospital of the Zhejiang University School of Medicine (ethical review code: Research 2014-113).

\section{Blood pressure measurement}

Blood pressure was measured in the right arm after resting for $10 \mathrm{~min}$ in a seated position, using an automated device (Omron 711, Dalian, China). At least three sitting BP measurements with a 30-second interval were taken and the average of the last two was used for analysis. Prehypertension was defined as BP between 120 and $139 \mathrm{~mm} \mathrm{Hg}$ systolic or 80 and $89 \mathrm{~mm} \mathrm{Hg}$ diastolic. Normal blood pressure was defined as BP values < 120/80 mm Hg.

\section{Laboratory test and assessment of metabolic factors}

All the subjects fasted overnight (at least $12 \mathrm{~h}$ ). Blood samples were collected into $5 \mathrm{ml}$ gel separator tubes (BD, USA) between 8 AM and 10 AM. Serum was subsequently isolated from the whole blood. Total cholesterol (CHO), high-density lipoprotein cholesterol (HDL-C), low-density lipoprotein cholesterol (LDL-C), triglycerides (TG), fasting blood glucose (FBG), serum creatinine (CR), uric acid (UA) and homocysteine (HCY) were analyzed with a Beckman AU5800 automatic analyzer (Beckman Coulter, Tokyo, Japan).

The following diagnostic criteria were employed as recommended for Chinese adults [22]. Overweight and obesity were defined as 24.0 $\leq$ to $\leq 27.9 \mathrm{~kg} / \mathrm{m}^{2}$ and body mass index (BMI) $\geq 28.0 \mathrm{~kg} / \mathrm{m}^{2}$ respectively. Hyperuricemia was defined as serum UA level $\geq 420 \mu \mathrm{mol} / \mathrm{l}$ for males and $\geq 360 \mu \mathrm{mol} / \mathrm{I}$ for females. Hyperglycemia was defined as FBG > $6.90 \mathrm{mmol} / \mathrm{l}$. Hyperhomocysteinemia was defined as HCY $\geq 10.0 \mu \mathrm{mol} / \mathrm{l}$ and high creatinine was defined as CR level $>115 \mu \mathrm{mol} / \mathrm{l}$ for males and > $107 \mu \mathrm{mol} / \mathrm{l}$ for females. Dyslipidemia was defined as TG $\geq 1.70 \mathrm{mmol} / \mathrm{l}$, $\mathrm{CHO}$ 
$\geq 5.70 \mathrm{mmol} / \mathrm{l}, \mathrm{LDL}-\mathrm{C} \geq 3.60 \mathrm{mmol} / \mathrm{l}$, or $\mathrm{HDL}-\mathrm{C}<$ $1.00 \mathrm{mmol} / \mathrm{l}[23]$.

\section{Statistical analysis}

Continuous data were presented as mean \pm SD or percentage. The relationships between the continuous variables of the different groups were analyzed using the $t$-test. Categorical variables were presented as a number (percentage). A $\chi^{2}$ test was used for the comparison of categorical variables. Multiple logistic regression analysis was used to evaluate the associations between prehypertension and metabolic variables. In addition, we used receiver operating characteristic curve (ROC) analyses to determine whether the risk factors have diagnostic accuracy for prehypertension. We first conducted a logistic regression to obtain the predicted probabilities for multivariate ROC analysis. We then tested whether the resulting area under the ROC curve (AUC) for combined variables is significantly better than any of the variables taken alone by using this saved probability as an indicator. The statistical analysis was performed using the IBM SPSS 20.0 software package, and $p$-values less than 0.05 were considered statistically significant.

\section{Results}

\section{General characteristics of study subjects}

Among all subjects studied, the incidence of prehypertension was $55.9 \%$ (66.9\% of men,

Table I. General characteristics of study subjects by blood pressure groups

\begin{tabular}{|c|c|c|c|}
\hline Characteristics & $\begin{array}{c}\text { Normal } \\
\text { blood pres- } \\
\text { sure } \\
(N=1716)\end{array}$ & $\begin{array}{l}\text { Prehyper- } \\
\text { tension } \\
(N=2175)\end{array}$ & $P$-value \\
\hline Age [years] & $42 \pm 9$ & $45 \pm 9$ & $<0.001$ \\
\hline $\mathrm{SBP}[\mathrm{mm} \mathrm{Hg}]$ & $112 \pm 7$ & $129 \pm 6$ & $<0.001$ \\
\hline $\mathrm{DBP}[\mathrm{mm} \mathrm{Hg}]$ & $67 \pm 6$ & $79 \pm 6$ & $<0.001$ \\
\hline BMI $\left[\mathrm{kg} / \mathrm{m}^{2}\right]$ & $22.6 \pm 2.7$ & $24.5 \pm 2.8$ & $<0.001$ \\
\hline $\mathrm{CHO}[\mathrm{mmol} / \mathrm{l}]$ & $4.82 \pm 0.87$ & $5.11 \pm 0.98$ & $<0.001$ \\
\hline $\mathrm{HDL}-\mathrm{C}[\mathrm{mmol} / \mathrm{l}]$ & $1.50 \pm 0.34$ & $1.44 \pm 0.34$ & $<0.001$ \\
\hline LDL-C [mmol/l] & $2.91 \pm 0.74$ & $3.23 \pm 0.81$ & $<0.001$ \\
\hline TG $[\mathrm{mmol} / \mathrm{l}]$ & $1.45 \pm 0.81$ & $1.85 \pm 1.18$ & $<0.001$ \\
\hline $\mathrm{CR}[\mu \mathrm{mol} / \mathrm{l}]$ & $65 \pm 14$ & $70 \pm 14$ & $<0.001$ \\
\hline $\mathrm{UA}[\mu \mathrm{mol} / \mathrm{l}]$ & $288 \pm 77$ & $328 \pm 84$ & $<0.001$ \\
\hline FBG [mmol/l] & $5.10 \pm 0.64$ & $5.40 \pm 1.02$ & $<0.001$ \\
\hline $\mathrm{HCY}[\mu \mathrm{mol} / \mathrm{l}]$ & $9.2 \pm 4.3$ & $10.1 \pm 4.7$ & $<0.001$ \\
\hline
\end{tabular}

Data are presented as mean $\pm S D$. SBP - systolic blood pressure, $D B P$ - diastolic blood pressure, $B M I$ - body mass index, $\mathrm{CHO}$ - total cholesterol, HDL-C - high-density lipoprotein cholesterol, LDL-C low-density lipoprotein cholesterol, $T G$-triglycerides, $C R$-creatinine, $U A$ - uric acid, FBG - fasting blood glucose, $\mathrm{HCY}$ - homocysteine.
$41.1 \%$ of women). General characteristics of the study subjects are shown in Table I. All the variables were significantly different between the two blood pressure groups $(p<0.001)$.

Comparison of the metabolic profile between the two groups (normal blood pressure group vs. prehypertension group) is shown in Table II. Subjects with prehypertension showed metabolic disorders such as dyslipidemia, hyperglycemia and hyperhomocysteinemia. Current smoking, overweight and obesity were also more frequent in prehypertensives compared to those with normal blood pressure. In men, the incidence of hyperuricemia was significantly higher in the prehypertension group than in the normal blood pressure group, whilst in women, there was no significant difference.

\section{Metabolic abnormalities associated with prehypertension}

Multiple logistic regression analysis revealed that prehypertension is associated with clusters of metabolic abnormalities including HDL-C $(\mathrm{OR}=1.550)$, $\mathrm{TG}(\mathrm{OR}=1.141)$, and FBG $(\mathrm{OR}=$ 1.320) after adjusting for age, sex, BMI and smoking (Table III). When the subjects were further divided by gender, the clusters of risk associations in prehypertension were different in men and in women. $\mathrm{CHO}(\mathrm{OR}=1.602)$ and $\mathrm{FBG}(\mathrm{OR}=1.205)$ were the risk factors associated predominantly with men who have prehypertension, while $\mathrm{HDL}-\mathrm{C}(\mathrm{OR}=1.729)$, TG $(\mathrm{OR}=1.314)$ and $\mathrm{FBG}$ $(O R=1.622)$ were the risk factors in women. In addition, to determine diagnostic accuracy of risk factors for prehypertension, we used ROC analysis. As shown in Figure 1, the AUCs of variables were as follows: age (AUC $=0.542,95 \% \mathrm{Cl}$ : $0.516-$ $0.569, p<0.001)$, BMI (AUC $=0.642,95 \% \mathrm{Cl}$ : $0.617-0.666, p<0.001), \mathrm{CHO}(\mathrm{AUC}=0.562,95 \%$ $\mathrm{Cl}: 0.537-0.588, p<0.001$ ), FBG (AUC $=0.587$, 95\% Cl: $0.562-0.613, p<0.001)$ in men and age $(\mathrm{AUC}=0.663,95 \% \mathrm{Cl}: 0.635-0.690, p<0.001), \mathrm{BMI}$ $(\mathrm{AUC}=0.646,95 \% \mathrm{Cl}: 0.619-0.674, p<0.001), \mathrm{HDL}-\mathrm{C}$ $(A \cup C=0.512,95 \% \mathrm{Cl}: 0.482-0.541, p<0.001)$, TG (AUC $=0.616,95 \% \mathrm{Cl}: 0.588-0.645, p<0.001)$, FBG (AUC $=0.609,95 \% \mathrm{Cl}: 0.580-0.637, p<0.001)$ in women. However, the AUCS of the linear combination model were $0.661(95 \% \mathrm{Cl}$ : 0.636-0.685, $p<0.001)$ for men and 0.716 (95\% Cl: 0.690$0.742, p<0.001)$ for women, which was superior to any of the variables considered alone.

\section{Discussion}

Our study suggested that prehypertension is associated with metabolic disorders and the risk factors were different between the two genders. Therefore, we suggest that in order to delay the progression of prehypertension to hypertension 
Table II. Comparison of the metabolic disorders of the two blood pressure groups

\begin{tabular}{|c|c|c|c|}
\hline Metabolic variables & $\begin{array}{c}\text { Normal blood pressure } \\
\qquad N(\%)\end{array}$ & $\begin{array}{l}\text { Prehypertension } \\
\qquad N(\%)\end{array}$ & $P$-value \\
\hline \multicolumn{4}{|l|}{ Overweight: } \\
\hline BMI: $24.0-27.9 \mathrm{~kg} / \mathrm{m}^{2}$ & $427(25.8)$ & $970(50.2)$ & $<0.001$ \\
\hline \multicolumn{4}{|l|}{ Obesity: } \\
\hline $\mathrm{BMI} \geq 28.0 \mathrm{~kg} / \mathrm{m}^{2}$ & $57(4.4)$ & $227(19.1)$ & $<0.001$ \\
\hline Current smoker & $346(20.2)$ & $609(28.0)$ & $<0.001$ \\
\hline \multicolumn{4}{|l|}{ Dyslipidemia: } \\
\hline $\mathrm{CHO} \geq 5.70 \mathrm{mmol} / \mathrm{l}$ & $266(15.5)$ & $546(25.1)$ & $<0.001$ \\
\hline $\mathrm{HDL}-\mathrm{C}<1.00 \mathrm{mmol} / \mathrm{l}$ & $75(4.4)$ & $134(6.2)$ & 0.014 \\
\hline $\mathrm{LDL}-\mathrm{C} \geq 3.60 \mathrm{mmol} / \mathrm{l}$ & 307 (17.9) & $652(30.0)$ & $<0.001$ \\
\hline $\mathrm{TG} \geq 1.7 \mathrm{mmol} / \mathrm{l}$ & $436(25.4)$ & $949(43.6)$ & $<0.001$ \\
\hline \multicolumn{4}{|l|}{ High creatinine: } \\
\hline $\mathrm{CR}>115 \mu \mathrm{mol} / \mathrm{l}$ for male & $1(0.14)$ & $0(0)$ & - \\
\hline CR $>107 \mu \mathrm{mol} / \mathrm{l}$ for female & $0(0)$ & $0(0)$ & - \\
\hline \multicolumn{4}{|l|}{ Hyperuricemia: } \\
\hline $\mathrm{UA}>420 \mu \mathrm{mol} / \mathrm{l}$ for male & $92(12.4)$ & $289(19.4)$ & $<0.001$ \\
\hline $\mathrm{UA}>360 \mu \mathrm{mol} / \mathrm{l}$ for female & $18(1.8)$ & $23(3.4)$ & $>0.05$ \\
\hline \multicolumn{4}{|l|}{ Hyperglycemia: } \\
\hline $\mathrm{FBG}>6.90 \mathrm{mmol} / \mathrm{l}$ & $18(1.0)$ & $84(3.9)$ & $<0.001$ \\
\hline \multicolumn{4}{|l|}{ Hyperhomocysteinemia: } \\
\hline $\mathrm{HCY} \geq 10.0 \mu \mathrm{mol} / / \mathrm{l}$ & $465(27.1)$ & $819(37.7)$ & $<0.001$ \\
\hline
\end{tabular}

Table III. Clusters of metabolic associations of prehypertension after adjusting for age, BMI, sex and smoking

\begin{tabular}{|c|c|c|c|c|c|}
\hline \multirow[t]{2}{*}{ Gender } & \multirow[t]{2}{*}{ Variables } & \multirow[t]{2}{*}{ OR } & \multicolumn{2}{|c|}{$95 \% \mathrm{Cl}$} & \multirow[t]{2}{*}{$P$-value } \\
\hline & & & Upper & Lower & \\
\hline \multirow[t]{5}{*}{ All } & Age & 1.027 & 1.018 & 1.035 & $<0.001$ \\
\hline & BMI & 1.185 & 1.151 & 1.221 & $<0.001$ \\
\hline & HDL-C & 1.550 & 1.186 & 2.205 & 0.001 \\
\hline & TG & 1.141 & 1.041 & 1.251 & 0.005 \\
\hline & FBG & 1.320 & 1.177 & 1.479 & $<0.001$ \\
\hline \multirow[t]{4}{*}{ Men } & Age & 1.014 & 1.003 & 1.025 & 0.013 \\
\hline & BMI & 1.208 & 1.163 & 1.256 & $<0.001$ \\
\hline & $\mathrm{CHO}$ & 1.602 & 1.210 & 2.121 & 0.001 \\
\hline & FBG & 1.205 & 1.057 & 1.374 & 0.005 \\
\hline \multirow[t]{5}{*}{ Women } & Age & 1.045 & 1.031 & 1.059 & $<0.001$ \\
\hline & BMI & 1.147 & 1.095 & 1.201 & $<0.001$ \\
\hline & HDL-C & 1.729 & 1.233 & 2.425 & 0.002 \\
\hline & TG & 1.314 & 1.093 & 1.581 & 0.004 \\
\hline & FBG & 1.622 & 1.319 & 1.995 & $<0.001$ \\
\hline
\end{tabular}


A

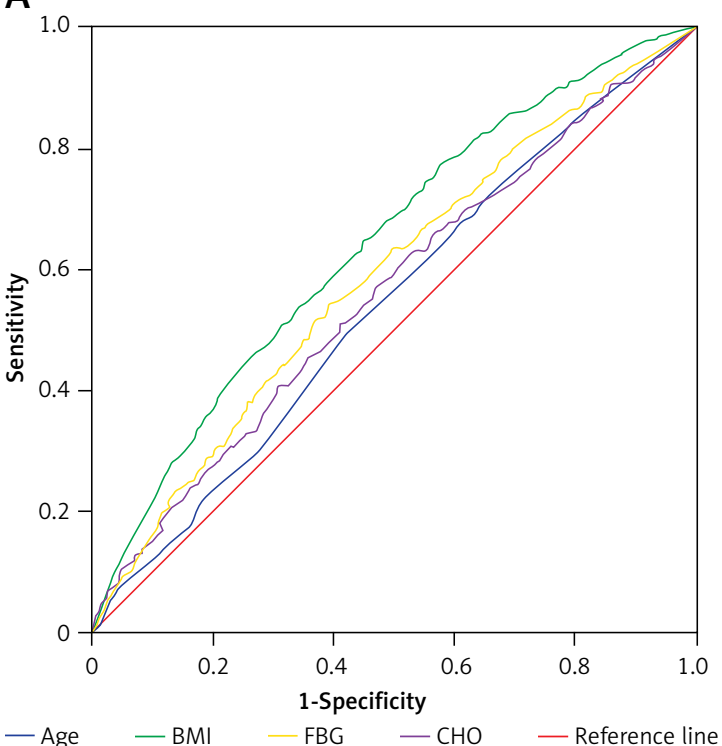

C

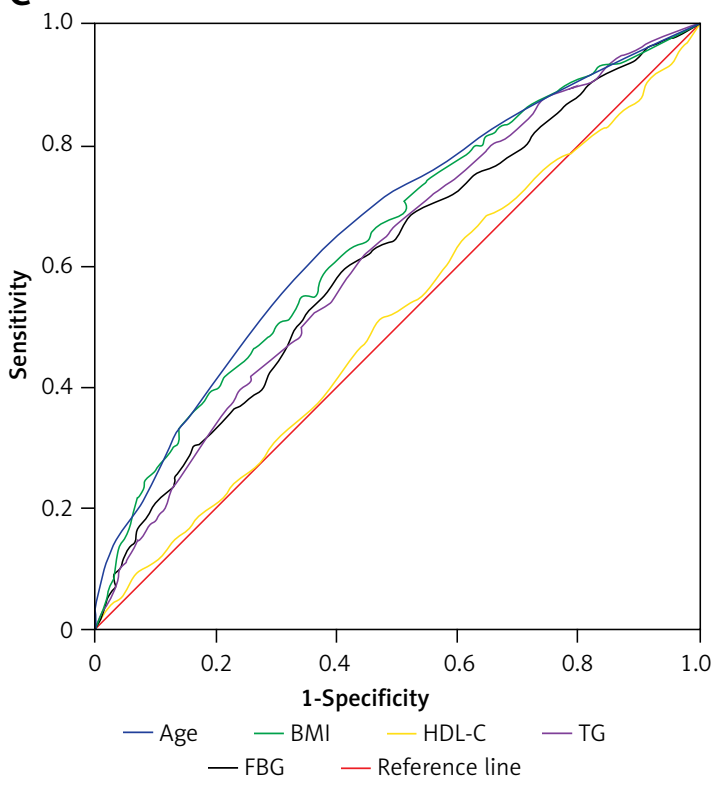

B

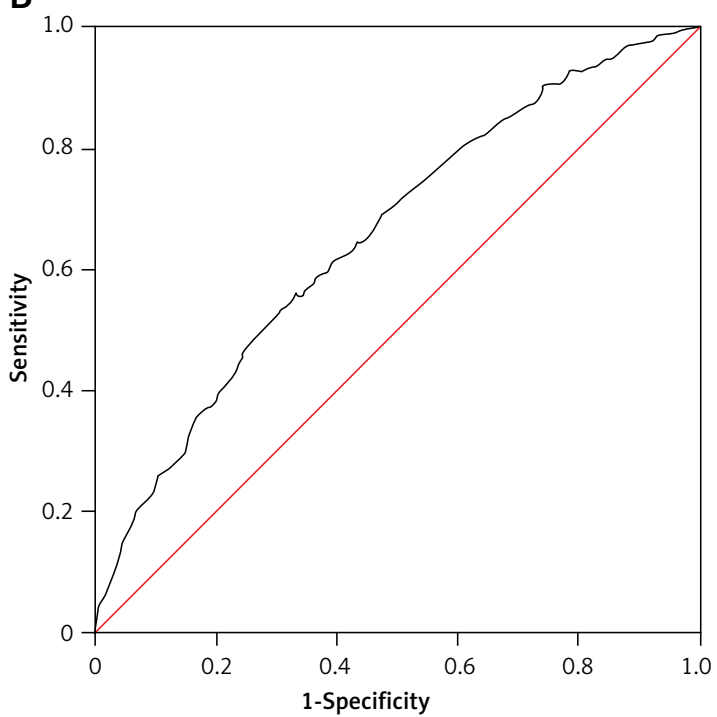

- Prediction model - Reference line

D

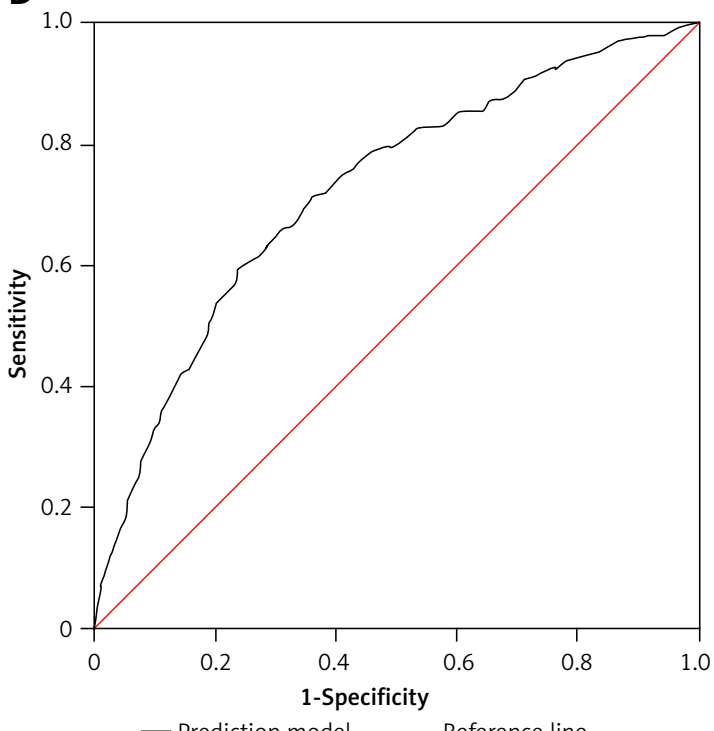

- Prediction model _ Reference line

Figure 1. Diagnostic accuracy for prehypertension. A - ROC curves of each variable for the prediction of prehypertension in men. B - Linear combination model of the four variables for the prediction of prehypertension in men. C - ROC curves of each variable for the prediction of prehypertension in women. D - Linear combination model of the five variables for the prediction of prehypertension in women

and decrease the risk of development of cardiovascular diseases, prevention strategies need to take into consideration the metabolic abnormalities that are present in subjects with prehypertension and this needs to be done in a gender-specific manner in order to prevent future development of hypertension and its associated complications.

Our study showed that the prevalence of prehypertension was $55.9 \%$ in Chinese adults, including $66.9 \%$ in men and $41.1 \%$ in women. Prehypertension is common and the incidence is likely to increase each passing year as the population ages since incidence of hypertension is known to increase with age. Thus, detecting and preventing prehypertension is an important public health issue that needs special attention in order to prevent future cardiovascular diseases. Higher levels of FBG, UA, CHO, LDL-C, TG and BMI are considered as potential risk factors present in those with prehypertension $[24,25]$. It was also reported that prehypertension is likely to be associated with other key risk factors of cardiovascular diseases such as hyperglycemia, dyslipidemia, male gender, older age, smoking, alcohol consumption, and hyperuricemia that may further aggravate future risk of cardiovascular diseases, especially in those 
with prehypertension [26, 27]. Consistent with the results of previous studies, we observed that age, BMI, HDL-C, TG and FBG are significantly associated with prehypertension. Most of these risk factors are associated with lifestyle. Therefore, changes in lifestyle should be recommended to those with abnormal blood pressure [28]. A recent study also suggested that high-intensity circuit training was effective in improving blood pressure, lipoproteins and triglycerides [29]. Health education, active management of blood pressure, timely and effective treatment of dyslipidemia, hyperuricemia or hyperglycemia and increasing physical activity should be adopted to delay the progression of prehypertension to hypertension [30].

A 5-year evaluation study suggested that age and gender were statistically significantly associated with BMI, systolic and diastolic hypertension, hyperglycemia, hypercholesterolemia and hypertriglyceridemia [31, 32]. Kim et al. reported that sociodemographic characteristics of prehypertension showed gender difference [33]. Therefore, one needs to consider whether metabolic abnormalities are seen in those with prehypertension and show possible differences between the two genders. In our study, we found that metabolic abnormalities observed in those with prehypertension did show gender differences. In men, $\mathrm{CHO}$ was significantly associated with prehypertension, while TG and HDL-C were independent risk factors in women. There is growing evidence to suggest that risk factors associated with elevated blood pressure may differ among men and women and with age of the individual. Natali et al. found that men with high normal BP had mildly elevated serum $\mathrm{CHO}$ compared with normal blood pressure, whereas women in this category had higher TG [34]. Therefore primary invention should be recommended for prehypertension according to the different risk factors present in different genders. The intervention strategies should be developed according to the clusters of metabolic characteristics in different genders rather than based on a single risk factor association. Based on the results of our present study, control of related factors may help prevent prehypertension or delay progress of hypertension and cardiovascular diseases.

There are some limitations to our study. First, most of the subjects were from Zhejiang province. Zhejiang province is relatively economically developed, and therefore the results are less representative of rural China. Second, this is a cross-sectional study. Hence, it is difficult to extrapolate the causal relationships between risk factors and the development of prehypertension. Also other confounders such as demographic and lifestyle habit factors were not available in our study.

In conclusion, the present cross-sectional analysis revealed that risk associations of prehyper- tension showed gender differences. FBG and $\mathrm{CHO}$ were the risk factors present in men with prehypertension, while abnormalities in FBG, TG and HDL-C were found in women. Therefore health education, active management of blood pressure and effective treatment of abnormal lipids are important strategies that need to be employed in the management of prehypertension.

\section{Acknowledgments}

This research project was supported by the Zhejiang Province Education Department Fund (No. Y201432814).

\section{Conflict of interest}

The authors declare no conflict of interest.

\section{References}

1. Chobanian AV, Bakris GL, Black HR, et al. The Seventh Report of the Joint National Committee on Prevention, Detection, Evaluation, and Treatment of High Blood Pressure: the JNC 7 report. JAMA 2003; 289: 2560-72.

2. Wang Y, Wang QJ. The prevalence of prehypertension and hypertension among US adults according to the new joint national committee guidelines: new challenges of the old problem. Arch Intern Med 2004; 164: 2126-34.

3. Ishikawa Y, Ishikawa J, Ishikawa S, et al. Prevalence and determinants of prehypertension in a Japanese general population: the Jichi Medical School Cohort Study. Hypertens Res 2008; 31: 1323-30.

4. Agyemang C, Owusu-Dabo E. Prehypertension in the Ashanti region of Ghana, West Africa: an opportunity for early prevention of clinical hypertension. Public Health 2008; 122: 19-24.

5. Egan BM, Stevens-Fabry S. Prehypertension: prevalence, health risks, and management strategies. Nat Rev Cardiol 2015; 12: 289-300.

6. Lüders S, Schrader J, Berger J, et al. The PHARAO study: prevention of hypertension with the angiotensin-converting enzyme inhibitor ramipril inpatients with high-normal blood pressure: a prospective, randomized, controlled prevention trial of the German Hypertension League. J Hypertens 2008; 26: 1487-96.

7. Julius S, Nesbitt SD, Egan BM, et al. Feasibility of treating prehypertension with an angiotensin receptor blocker. N Engl J Med 2006; 354: 1685-97.

8. Vasan RS, Larson MG, Leip EP, et al. Impact of high-normal blood pressure on the risk of cardiovascular disease. N Engl J Med 2001; 345: 1291-7.

9. Washio M, Tokunaga S, Yoshimasu K, et al. Role of prehypertension in the development of coronary atherosclerosis in Japan. J Epidemiol 2004; 14: 57-62.

10. Qureshi Al, Suri MF, Kirmani JF, Divani AA, Mohammad $Y$. Is prehypertension a risk factor for cardiovascular diseases. Stroke 2005; 36: 1859-63.

11. Zhang Y, Lee ET, Devereux RB, et al. Prehypertension, diabetes, and cardiovascular disease risk in a population-based sample: the Strong Heart Study. Hypertension 2006; 47: 410-4.

12. Grotto I, Grossman E, Huerta M, Sharabi Y. Prevalence of prehypertension and associated cardiovascular risk 
profiles among young Israeli adults. Hypertension 2006; 48: 254-9.

13. Huang Y, Cai X, Li Y, et al. Prehypertension and the risk of stroke: a meta-analysis. Neurology 2014; 82: 1153-61.

14. Faselis C, Doumas M, Kokkinos JP, et al. Exercise capacity and progression from prehypertension to hypertension. Hypertension 2012; 60: 333-8.

15. Habib GB, Virani SS, Jneid H. Is 2015 the primetime year for prehypertension? Prehypertension: a cardiovascular risk factor or simply a risk marker? J Am Heart Assoc 2015; 4: pii: e001792.

16. Xu T, Liu J, Zhu G, Liu J, Han S. Prevalence of prehypertension and associated risk factors among Chinese adults from a large-scale multi-ethnic population survey. BMC Public Health 2016; 16: 775.

17. Meng XJ, Dong GH, Wang D, et al. Epidemiology of prehypertension and associated risk factors in urban adults from 33 communities in China - the CHPSNE study. Circ J 2012; 76: 900-6.

18. Tabrizi JS, Sadeghi-Bazargani H, Farahbakhsh M, Nikniaz L, Nikniaz Z. Prevalence and associated factors of prehypertension and hypertension in Iranian population: the Lifestyle Promotion Project (LPP). PLoS One 2016; 11: e0165264.

19. Parthaje PM, Unnikrishnan B, Thankappan KR, Thapar $R$ Fatt QK, Oldenburg B. Prevalence and correlates of prehypertension among adults in urban South India. Asia Pac J Public Health 2016; 28: 93S-101S.

20. Alkerwi A, Baydarlioglu B, Sauvageot N, et al. Smoking status is inversely associated with overall diet quality: findings from the ORISCAV-LUX study. Clin Nutr 2016; 16: 30212-6

21. Oda N, Kajikawa M, Maruhashi T, et al. Endothelial function is impaired in relation to alcohol intake even in the case of light alcohol consumption in Asian men. Flow-mediated Dilation Japan (FMD-J) Study. Int J Cardiol 2017; 230: 523-8.

22. Liu LS, Writing Group of 2010 Chinese Guidelines for the Management of Hypertension. [2010 Chinese guidelines for the management of hypertension]. Zhonghua Xin Xue Guan Bing Za Zhi 2011; 39: 579-615.

23. Teramoto T, Sasaki J, Ueshima H, et al. Diagnostic criteria for dyslipidemia. Executive summary of Japan Atherosclerosis Society (JAS) guideline for diagnosis and prevention of atherosclerotic cardiovascular diseases for Japanese. J Atheroscler Thromb 2007; 14: 155-8.

24. Isezuo SA, Sabir AA, Ohwovorilole AE, Fasanmade OA. Prevalence, associated factors and relationship between prehypertension and hypertension: a study of two ethnic African populations in Northern Nigeria. J Hum Hypertens 2011; 25: 224-30.

25. Wang R, Lu X, Hu Y, You T. Prevalence of prehypertension and associated risk factors among health check-up population in Guangzhou, China. Int J Clin Exp Med 2015; 8: 16424-33.

26. Chockalingam A, Ganesan N, Venkatesan S, et al. Patterns and predictors of prehypertension among "healthy" urban adults in India. Angiology 2005; 56: 557-63.

27. Peng H, Ding J, Peng Y, et al. Hyperuricemia and microalbuminuria are separately and independently associated with prehypertension among Chinese Han women. Metab Syndr Relat Disord 2012; 10: 202-8.

28. Collier SR, Landram MJ. Treatment of prehypertension: lifestyle and/or medication. Vasc Health Risk Manag 2012; 8: 613-9.

29. Paoli A, Pacelli QF, Moro T, et al. Effects of high-intensity circuit training, low-intensity circuit training and endurance training on blood pressure and lipoproteins in middle-aged overweight men. Lipids Health Dis 2013; 12: 131.

30. Beck DT, Martin JS, Casey DP, Braith RW. Exercise training improves endothelial function in resistance arteries of young prehypertensives. J Hum Hypertens 2014; 28: 303-9.

31. Poorolajal J, Zamani R, Mir-Moeini R, et al. Five year evaluation of chronic diseases in Hanadan, Iran: 2005-2009. Iran J Public Health 2012; 41: 71-81.

32. Ghomari-Boukhatem H, Bouchouicha A, Mekki K, Chenni K, Belhadj M, Bouchenak M. Blood pressure, dyslipidemia and inflammatory factors are related to body mass index in scholar adolescents. Arch Med Sci 2017; 13: 46-52.

33. Kim Y, Lee S. Prevalence and risk factors associated with prehypertension by gender and age in a Korean population in the KNHANES 2010-2012. Iran J Public Health 2015; 44: 1594-602.

34. Natali A, Muscelli E, Casolaro A, et al. Metabolic characteristics of prehypertension: role of classification criteria and gender. J Hypertens 2009; 27: 2394-402. 